\title{
ÍNDICE ANUAL 2014 \\ Problemas del desarrollo \\ REVISTA LATINOAMERICANA DE ECONOMÍA \\ VOLUMEN 45
}

\begin{abstract}
ARTículos
Alarco, Germán (2014), Salarios reales, balanza de pagos y producto potencial en América Latina, 1980-2011, núm. 179, México, IIEc-UnAM, octubre-diciembre, pp. 65-90.

Azamar, Aleida y José Ignacio Ponce (2014), Extractivismo y desarrollo: los recursos minerales en México, núm. 179, México, IIEc-UnAM, octubre-diciembre, pp. 137-158.

Beccaria, Luis y Roxana Maurizio (2014), Hacia la protección social universal en América Latina. Una contribución al debate actual, núm. 177, México, IIEcUNAM, abril-junio, pp. 37-58.

Bekerman, Marta, Federico Dulcich y Nicolás Moncaut (2014), La emergencia de China y su impacto en las relaciones comerciales entre Argentina y Brasil, núm. 176, México, IIEc-UnAM, enero-marzo, pp. 55-82.

Belloni, Paula y Andrés Wainer (2014), El rol del capital extranjero y su inserción en la América del Sur posneoliberal, núm. 177, México, IIEc-UNAM, abril-junio, pp. 87-112.

Berumen, Sergio A. (2014), Impacto de la crisis en el desarrollo económico de las regiones mineras en Europa, núm. 176, México, IIEc-UNAM, enero-marzo, pp. 83-106.

Carrasco, Carlos (2014), Origen de los desequilibrios macroeconómicos en la economía española, núm. 179, México, IIEc-UNAM, octubre-diciembre, pp. 91-115.

Cruz Moritz y Mayrén Polanco (2014), El sector primario y el estancamiento económico en México, núm. 178, México, IIEc-UnAM, julio-septiembre, pp. 9-34.
\end{abstract}


Cueva, Marcos (2014), Moneda y crisis: un enfoque, núm. 178, México, IIEcUNAM, julio-septiembre, pp. 163-180.

Diego Quintana, Roberto (2014), Actores sociales rurales y la nación mexicana frente a los megaproyectos mineros, núm. 179, México, IIEc-UnAM, octubre-diciembre, pp. 159-180.

Fresnada, Edel J. (2014), Migrantes en el socialismo: el desarrollo cubano a debate, núm. 176, México, IIEc-UnAM, enero-marzo, pp. 107-132.

De Souza, Marcos José, Elaine Fernandes y Licas Vitor de Carvalho (2014), Determinantes estructurales en la difusión de las patologías del agua en Brasil, núm. 179, México, IIEc-UnAM, octubre-diciembre, pp. 117-136.

García, Aída e Ignacio Perrotini (2014), Modus operandi del Nuevo Consenso Macroeconómico en Brasil, Chile y México, núm. 179, México, IIEc-unam, octubre-diciembre, pp. 35-63.

Gasca, José y Felipe Torres (2014), El control corporativo de la distribución de alimentos en México, núm. 176, México, IIEc-UnAM, enero-marzo, pp. 133156.

Gaulard, Mylène (2014), La burbuja inmobiliaria en China, núm. 178, México, IIEC-UNAM, julio-septiembre, pp. 63-87.

Groisman, Fernando (2014), Empleo, salarios y desigualdad en Argentina: análisis de los determinantes distributivos, núm. 177, México, IIEc-UNAM, abril-junio, pp. 59-86.

Hongbo, Sun (2014), Modelo de cooperación energética entre China y América Latina, núm. 176, México, IIEc-UnAM, enero-marzo, pp. 9-30.

Iglesias, Esther (2014), Travesías del desarrollo en Yucatán, núm. 177, México, IIEC-UNAM, abril-junio, pp. 169-192.

Juárez-Hernández, Sergio y Gabriel León (2014), Energía eólica en el istmo de Tehuantepec: desarrollo, actores y oposición social, núm. 178, México, IIEcUNAM, julio-septiembre, pp. 139-162. 
Kennedy, Damián (2014), Producción y apropiación del valor en Argentina: el rol del deprimido salario real, núm. 176, México, IIEc-UnAM, enero-marzo, pp. 157-182.

Lavarello, Pablo (2014), Convergencia de paradigmas biotecnológicos y estrategias de los grupos líderes mundiales, núm. 177, México, IIEc-UnAM, abril-junio, pp. 9-36.

Mateo, Juan Pablo y Santiago García (2014), El sector petrolero en Ecuador. 2000-2010, núm. 177, México, IIEc-Unam, abril-junio, pp. 113-140.

Mattos, Fernando y Bruno Fevereiro (2014), ¿Se desindustrializa Brasil?, núm. 178, México, IIEc-UnAm, julio-septiembre, pp. 35-62.

Orraca, Pedro (2014), El trabajo infantil en México y sus causas, núm. 178, México, IIEc-UnAm, julio-septiembre, pp. 113-138.

Pérez Laurrabaquio, Oscar (2014), Relación no lineal entre la inflación y crecimiento económico: la experiencia de México, núm. 177, México, IIEc-Unam, abril-junio, pp. 141-168.

Rivera Ríos, Miguel Ángel (2014), Desarrollo económico y trayectorias históricas. Una aproximación al caso de Brasil y México, núm. 179, México, IIEcUNAM, octubre-diciembre, pp. 9-33.

Santos, María Emma (2014), El indice multidimensional y trampas de pobreza en el Cono Sur, núm. 178, México, IIEc-UnAM, julio-septiembre, pp. 89-112.

Sidorenko, Tatiana (2014), Cooperación económica entre Rusia y China: alcances y perspectivas, núm. 176, México, IIEc-UnAM, enero-marzo, pp. 31-54.

\section{RESEÑAS}

Álvarez, Cruz (2014), Encrucijadas, prospectivas y propuestas sobre la seguridad social en México, Berenice P. Ramírez y Roberto Ham Chande (coords.), núm. 176, México, IIEc-UnAm, enero-marzo, pp. 192-194.

Atempa, Diana (2014), Migración internacional. Algunos desafios, Ana María Aragonés (coord.), núm. 176, México, IIEc-UnAM, enero-marzo, pp. 195-197. 
Barragán, Alejandro (2014), Ciencia, tecnología e innovación en el desarrollo de México y América Latina. Desafíos de la ciencia, la tecnología y la innovación. Desarrollo, educación y trabajo, tomo I, María del Carmen del Valle, Ana Mariño, Ismael Núñez (coords.), núm. 178, México, IIEc-UNAM, julio-septiembre, pp. 189-191.

Bautista, Nallely (2014), Evaluación de la politica de acceso al agua potable en el Distrito Federal, Arsenio González (coord.), núm. 176, México, IIEc-Unam, enero-marzo, pp. 189-191.

Concha, Elizabeth (2014), Tras la crisis, politicas públicas a favor del crecimiento económico, Alma Chapoy y Patricia Rodríguez (coords.), colección de Libros Problemas del Desarrollo, núm. 178, México, IIEc-Unam, julio-septiembre, pp. 183-185.

González, Francisco (2014), El neoliberalismo y su crisis. Causas, escenarios y posibles desenvolvimientos, Jaime Estay, Claudio Lara y Consuelo Silva (eds.), núm. 178, México, IIEc-UnAM, julio-septiembre, pp. 181-182.

Hernández, Santiago (2014), Feminismo y cambio social en América Latina y el Caribe, Alba Carosio (coord.), núm. 176, México, IIEc-unam, enero-marzo, pp. 183-185.

Hernández, Santiago (2014), Acumulación de capital y distribución del ingreso, Cesar Salazar, núm. 179, México, IIEc-UnaM, octubre-diciembre, pp. 181183.

Juárez, Diego (2014), Estrategias para un desarrollo sustentable frente a las tres crisis: finanzas, economía y medio ambiente, E. Correa, A. Girón, A. Guillén y A. Ivanova (coordinadores), núm. 179, México, IIEc-UNAM, octubre-diciembre, pp. 184-186.

López, Marco Antonio (2014), La crisis mundial y sus efectos en México: análisis sectoriales y regionales, Alejandro Álvarez y Germán Sánchez (coords.), núm. 179, México, IIEc-UnAM, octubre-diciembre, pp. 187-189.

Mañán, Oscar (2014), Socialismo o muerte, William Yohai, núm. 178, México, IIEC-UNAM, julio-septiembre, pp. 186-188. 
Maya, José Luis (2014), Los problemas actuales de la economía nacional, Gustavo López Pardo y Verónica Villarespe (coords.), núm. 177, México, IIEcUNAM, abril-junio, pp. 202-204.

Mazari, Marisa (2014), Agricultura y contaminación del agua, Rosario Pérez Espejo y Alonso Aguilar (coords.), núm. 177, México, IIEc-UnAM, abril-junio, pp. 199-201.

Olmos, Rafael (2014), El desarrollo económico de las Regiones Medias de México, Adolfo Sánchez Almanza (coord.), núm. 179, México, IIEc-UnAM, octubrediciembre, pp. 193-195.

Palazuelos, Antonio (2014), Fracturas y crisis en Europa, Ignacio Álvarez, Fernando Luengo y Jorge Uxó, núm. 177, México, IIEc-UnAM, abril-junio, pp. 205-207.

Quintana, Aderak (2014), El reto del siglo XXI, regular el sistema financiero global, Alicia Girón y Eugenia Correa (coords.), núm. 177, México, IIEc-UnAM, abril-junio, pp. 193-195.

Rodríguez, Isabel (2014), Dinero, estructuras financieras y financiarización un debate teórico institucional, Noemi Levy, núm. 179, México, IIEc-UnaM, octubre-diciembre, pp. 190-192.

Sánchez, Iván (2014), Informalidad urbana e incertidumbre. ¿Cómo estudiar la informalización en las metrópolis?, Felipe de Alba y Frédéric Lesemann (coords.), núm. 176, México, IIEc-UnAM, enero-marzo, pp. 186-188.

Tolentino, Jessica (2014), Ciencia, tecnología e innovación en el desarrollo de México y América Latina. Desafíos de la ciencia, la tecnología y la innovación. Desarrollo, educación y trabajo, tomo II, María del Carmen del Valle, Ana Mariño, Ismael Núñez (coords.), núm. 178, México, IIEc-UnAM, julio-septiembre, pp. 192-194.

Zavaleta, Josué (2014), Migración y desarrollo. Debates y propuestas, Ana María Aragonés (coord.), núm. 177, México, IIEc-UnAM, abril-junio, pp. 196-198. 
